\title{
Electrospun chitosan-based nanofibres for removal of phenols from drinking water
}

\author{
Lebea N Nthunya ${ }^{1,2}$, Monaheng L Masheane ${ }^{1,2}$, Soraya P Malinga', Edward N Nxumalo², Sabelo D Mhlanga ${ }^{2 *}$ \\ 'Department of Applied Chemistry and the DST/Mintek Nanotechnology Innovation Centre-Water Research Node, University of Johannesburg, \\ PO Box 17011, Doornfontein, 2028, Johannesburg, South Africa \\ ${ }^{2}$ Nanotechnology and Water Sustainability Research Unit, College of Science, Engineering and Technology, University of South Africa,
}

Florida, 1709, Johannesburg, South Africa

\begin{abstract}
Chitosan-based nanofibres were synthesized using a fibre electrospinning technique and tested for the removal of 3-methyl4-nitrophenol from aqueous solutions. The downside of chitosan-based materials is swelling. In this study, it was found that the addition of polyisoprene not only improved the electrospinning ability of chitosan but also reduced the swelling of the nanofibres by $50 \%$. The adsorption studies of 3-methyl-4-nitrophenol on the chitosan-based nanofibres were conducted in a batch process. The nanofibres were found to remove up to $90 \%$ of 3-methyl-4-nitrophenol with an adsorption reduction capacity of $12 \%$ at each cycle of reusability test. The reduction capacity was associated with the chemical interaction of the adsorbate and the adsorbent. This indicated that the nanofibres can effectively remove 3-methyl-4-nitrophenol from water for at least 3 cycles. The adsorption efficiency improved as the degree of cross-linking was reduced and the adsorption mechanism followed the Freundlich isotherm suggesting that the adsorption of 3-methyl-4-nitrophenol occurred in different layers on the surface of the nanofibres. The degree of crosslinking of the electrospun nanofibres with glutaraldehyde was found to affect the adsorption capacity. Nanofibres with different degrees of crosslinking were used to study the effect of $\mathrm{pH}$, adsorbent dose, and initial concentration.
\end{abstract}

Keywords: 3-methyl-4-nitrophenol, adsorption, chitosan nanofibres, the degree of cross-linking, removal efficiency

\section{INTRODUCTION}

Water is a vital life-sustaining solvent. Therefore, water must be free from pollutants and it must be available in adequate amounts. However, water pollution is becoming a global concern (Nthunya et al., 2017). Organic pollutants such as phenols are among the water pollutants that pose a threat to human health (Sartori et al., 2012).

Phenols occur naturally during the decomposition of organic matter and UV irradiation of the amino acids in the hemicelluloses of plants. However, their concentration is escalated by anthropogenic activities which include burning of fossil fuels, treatment of pests and manufacturing of chemicals such as paracetamol (Olujimi et al., 2010; Richter et al., 2000). They enter water bodies via different pathways, which include industrial effluents (Rajaram and Das, 2008), urban run-off (Sulej et al., 2012) and agricultural run-off (Olujimi et al., 2010).

Phenols undergo chemical conversions in water sources, which elevates their hazardous effects at equivalent concentrations to their counterparts. Rainwater containing high levels of nitrogen oxides (e.g. $\mathrm{NO}$ and $\mathrm{NO}_{2}$ ) oxidizes phenols to nitrophenols (e.g. 4-nitrophenol, 3-methyl-4nitrophenol, etc), which further increases the concentration of nitrophenols in the water sources (Michałowicz and Duda 2007; WHO, 2011). For example, nitrophenol, which is used as an intermediate for the production of pesticides, is reported to be released into water and air from its production site after biological treatment (Michałowicz and Duda, 2007). The

\footnotetext{
To whom all correspondence should be addressed.

용 +27114712104

e-mail: mhlansd@unisa.ac.za

Received 7 September 2016; accepted in revised form 11 June 2018
}

nitrophenols are known to be more toxic to human beings than the pristine phenols (i.e. carbolic acid).

Several methods have been used for the removal of phenols from water. These include photo-degradation (Nie et al., 2012), membrane technology (Teli et al., 2013), coagulation and flocculation (El-Ashtoukhy et al., 2013) as well as adsorption (Li et al., 2009). Adsorption has gained more attention for the removal of phenols and other organics due to high adsorption efficiency, ease of operation, cost-effectiveness and high pollutant selectivity. Among other adsorbents, chitosan (CS) has been extensively explored due to its availability in abundance, biocompatibility, biodegradability, ease of chemical modification and recyclability (Zhou et al., 2011; Sun and Li, 2011; Venkatesan and Kim, 2010).

However, CS-based nanocomposites have shown high swelling capacities when subjected to water (Xie and Wang, 2010) and cannot be electrospun as is. This limits their application in water treatment. To overcome these problems, we synthesized less swelling CS nanofibres by carefully selecting a recipe of compatible polymers that were added to the CS solution (in optimized amounts) to make it electrospinnable (Nthunya et al. 2017). The CS-based nanofibres were then tested for their efficacy to remove 3-methyl-4-nitrophenol from water.

\section{EXPERIMENTAL}

\section{Materials}

Chitosan (MW; $150000 \mathrm{~g} \cdot \mathrm{mol}^{-1}, 75$ degree of deacetylation), polyisoprene, cis (MW; 35000$)$, polyacrylamide (MW; $\left.700000 \mathrm{~g} \cdot \mathrm{mol}^{-1}\right)$, polyethylene glycol $\left(\mathrm{MW} ; 6600 \mathrm{~g} \cdot \mathrm{mol}^{-1}\right)$, glutaraldehyde $(25 \% \mathrm{w} / \mathrm{v})$, glacial acetic acid $(99.9 \% \mathrm{w} / \mathrm{v})$, 3-methyl-4-nitrophenol (analytical standard, 98\%) were 
purchased from Sigma Aldrich (Dusseldorf, Germany). PVDF durapore filter membranes with the pore size of $0.22 \mu \mathrm{m}$ and diameter of $47 \mathrm{~mm}$ were purchased from Merck (Massachusetts, USA). $\mathrm{C}_{18}$ SPE cartridges (bed I.D. = $4 \mathrm{~mm}$, thickness $=0.75 \mathrm{~mm}$, particle size $=50 \mu \mathrm{m}$ and $60 \AA$ pore size) were purchased from $3 \mathrm{M}$ Company (Minnesota, USA), deionized water was prepared in our laboratory using direct-Q (Millipore) system supplied by Merck Millipore (Massachusetts, USA).

\section{Electrospinning and cross-linking of nanofibres}

CS-based nanofibres were synthesized using an electrospinning technique. A 3\% chitosan/poly(acrylamide) (CS/PAA) polymer solution at the percentage ratio of 77:23 was prepared by dissolving the respective polymers in $50 \%$ acetic acid $\left(\mathrm{CH}_{3} \mathrm{COOH}\right)$ as the electrospinning solution. 5\% of polyethylene glycol (PEG) and 80\% polyisoprene (PIP) relative to CS were added to reduce the surface tension and the swelling of CS. To form CS-based nanofibres, the prepared solutions were transferred to a $10 \mathrm{~mL}$ plastic syringe fitted with a needle of $0.8 \mathrm{~mm}$ internal diameter. The syringe was placed on NE-4000 double syringe pump. A high-voltage generator was used to induce an electric field between the collecting plate and the tip of the needle. The positive terminal of the DC generator was connected to the tip of the syringe needle and the negative terminal connected to the aluminium foil (collecting plate). The earth terminals were connected to the syringe pump. The nanofibres were synthesized at the following optimized electrospinning conditions: the syringe injection flow rate of $0.7 \mathrm{~mL} \cdot \mathrm{h}^{-1}$, a distance of $21 \mathrm{~cm}$ between the aluminium foil and the tip of the needle, and a voltage of $24 \mathrm{kV}$ at room temperature. The electrospun CS nanofibres were dried in an oven at $40^{\circ} \mathrm{C}$ for $24 \mathrm{~h}$ to remove moisture. The nanofibres were placed and supported at the top of the beaker which was saturated with the vapour of $25 \%$ glutaraldehyde (GLA) for $24 \mathrm{~h}$. The resulting cross-linked nanofibres were dried in an oven for $24 \mathrm{~h}$.

\section{Characterization}

The CS-based nanofibres were characterized using scanning electron microscopy (SEM), transmission electron microscopy (TEM), Fourier transform infrared spectroscopy (FTIR), Raman spectroscopy, thermogravimetric analysis (TGA), X-ray diffraction (XRD) and a tensile tester. The characterizations were performed to understand the morphology, dispersion of nanoparticles on the nanofibres, polymerization, functionality, thermal degradation, mechanical strength and the swelling behaviour the nanofibres. The detailed characterization results for CS-based nanofibres are available in Nthunya et al. (2017) and Masheane et al. (2016).

\section{Swelling tests}

To perform this analysis, $1.5 \mathrm{~g}$ of the CS-based nanofibres was carefully weighed and immersed in $10 \mathrm{~mL}$ of de-ionized water in a conical flask for $24 \mathrm{~h}$ at room temperature. The nanofibres were removed from the water, blotted and re-weighed. The swelling ratio of the nanofires was computed using Eq. 1 (Liu et al., 2013).

$$
Q=\frac{M_{s}-M_{d}}{M_{d}} 100 \%
$$

where:

$Q=$ swelling ratio in percentages

$M_{s}=$ the mass in the swollen state

$M_{d}=$ the mass in the dry state

\section{Solid phase extraction (SPE)}

The adsorption studies of phenols were conducted in water. Therefore, 3-methyl-4-nitrophenol was used as an indicator compound for phenols and extracted from water using the SPE manifold and $\mathrm{C}_{18}$ cartridges. The cartridges were pre-conditioned by passing $5 \mathrm{~mL}$ of methanol and water consecutively. Water samples $(100 \mathrm{~mL})$ were passed through the cartridges under moderate vacuum pressure. The cartridges were washed with de-ionized water and air-dried for $20 \mathrm{~min}$. 3-methyl-4-nitrophenol was eluted into the calibrated vials using ethyl acetate $(1 \mathrm{~mL})$ followed by methanol $(1 \mathrm{~mL})$ (Geibler and Scholar 1994). The eluted samples were dried under nitrogen gas. Dichloromethane (DCM) $(2 \mathrm{~mL})$ was added to the vials and vortexed for $20 \mathrm{~min}$. The SPE extracts were then injected into the GCxGC-TOF MS instrument described in the forthcoming section.

\section{Gas chromatography and mass spectrometry analysis}

A LECO comprehensive two-dimensional gas chromatograph coupled to time-of-flight mass spectrometer (GCxGC-TOFMS) was used for the analysis and quantification of 3-methyl-4nitrophenol. This is mainly because GC×GC-TOFMS has been proven to present some advantages for the analysis of complex mixtures (e.g. phenols) such as increased peak capacity, sensitivity, selectivity and the possibility of having an organized distribution of structurally-related chromatographic peaks. Restek RXi 5Sil-MS and RXi 17-Sil-MS (both with the following specifications: $30 \mathrm{~m}$, internal diameter of $0.25 \mathrm{~mm}$ and film thickness of $0.25 \mu \mathrm{m}$ ) were used as primary and secondary columns, respectively. These columns were chosen because the former has high sensitivity, high thermal stability and reduced bleeds which prevent oxidation of the column, while the latter has excellent inertness and selectivity for phenols. The temperature of the primary column was started at $55^{\circ} \mathrm{C}$ for $5 \mathrm{~min}$, then increased to $280^{\circ} \mathrm{C}$ at the rate of $10^{\circ} \mathrm{C} \cdot \mathrm{min}^{-1}$ and held for $5 \mathrm{~min}$. The temperature of the secondary column was started at $75^{\circ} \mathrm{C}$ and held for $5 \mathrm{~min}$, then increased to $300^{\circ} \mathrm{C}$ at the rate of $10^{\circ} \mathrm{C} \cdot \mathrm{min}^{-1}$. The modulator interface temperature was set at $30^{\circ} \mathrm{C}$ above the secondary oven temperature. The transfer line was set at $300^{\circ} \mathrm{C}$ and the ion source temperature at $240^{\circ} \mathrm{C}$. The electron impact ionization energy was set at $-70 \mathrm{eV}$ with an offset of $300 \mathrm{~V}$ making a total detector voltage of $1600 \mathrm{~V}$. Helium was used as the carrier gas (Geibler and Scholar, 1994).

\section{Calibration}

Standards were prepared using 3-methyl-4-nitrophenol in DCM. The working standards used to draw the calibration graphs were prepared from the serial dilution of the stock solution to the required concentration. A total of 7 working standards $\left(0.5 \mathrm{mg} \cdot \mathrm{L}^{-1}, 1 \mathrm{mg} \cdot \mathrm{L}^{-1}, 2 \mathrm{mg} \cdot \mathrm{L}^{-1}, 5 \mathrm{mg} \cdot \mathrm{L}^{-1}, 10 \mathrm{mg} \cdot \mathrm{L}^{-1}\right.$, $\left.20 \mathrm{mg} \cdot \mathrm{L}^{-1}, 60 \mathrm{mg} \cdot \mathrm{L}^{-1}\right)$ was used for preparation of calibration graphs. The determination coefficient of approximately 0.99 
was obtained from the linear plot. This calibration curve was used for quantification of the extracted 3-methyl-4-nitrophenol from the adsorption water samples.

\section{Batch adsorption experiments}

The adsorption of 3-methyl-4-nitrophenol was conducted using glutaraldehyde (GLA) cross-linked CS-based nanofibres under optimised conditions. To do this, a measured mass of the nanofibres and 3-methyl-4-nitrophenol $(25 \mathrm{~mL})$ were transferred into a conical flask. The contents of the flask were stirred. After stirring, the solution containing 3-methyl-4nitrophenol was separated from the nanofibres and the filtrate was ready for SPE extraction of 3-methyl-4-nitrophenol. The effect of solution $\mathrm{pH}(5-11)$, adsorbent dose (50-400 mg), contact time (0-210 $\mathrm{min})$ and initial concentration (40-100 $\left.\mathrm{mg} \cdot \mathrm{L}^{-1}\right)$ of 3-methyl-4-nitrophenol were studied. To determine the effect of individual parameters (for example, the effect of $\mathrm{pH}$ ), the other parameters were kept constant while the parameter of interest was varied at the above-given ranges. 25 $\mathrm{mL}$ aliquots of 3-methyl-4-nitrophenol $\left(100 \mathrm{mg} \cdot \mathrm{L}^{-1}\right)$ were used for all adsorption experiments to ascertain the adsorption in the laboratory. The concentration of 3-methyl-4-nitrophenol was determined using GCxGC-TOFMS. Kinetic studies for the adsorption of 3-methyl-4-nitrophenol were conducted and isotherm models were used to determine the adsorption mechanism of the CS-based nanofibres. The adsorption efficiency of the CS-based nanofibres was calculated using Eqs $2-5$, where the initial mass of 3-methyl-4-nitrophenol was prepared from the serial dilutions of the stock solution and final concentrations were determined using GCxGC-TOFMS.

$$
\text { Adsorption efficiency }=\frac{\text { Mass of nitrophenol absorbed }}{\text { Initial mass of nitrophenol }} \times 100 \%
$$

where:

Mass of nitrophenol adsorbed (mg) = Initial mass (mg) - final mass (mg)

Initial mass $(\mathrm{mg})=$ Initial concentration (nitrophenol, $\mathrm{mg} \cdot \mathrm{L}^{-1}$ ) $\times$ volume taken $(\mathrm{mL})$

Final mass $(\mathrm{mg})=$ Final concentration (nitrophenol, $\left.\mathrm{mg} \cdot \mathrm{L}^{-1}\right)$

$$
\times \text { volume taken }(\mathrm{mL})
$$

\section{Kinetics}

The rates of adsorption of 3-methyl-4-nitrophenol using CS-based nanofibres were determined using pseudo-first-order kinetics and pseudo-second-order kinetic models. The equation for the kinetics of the pseudo-first-order used is provided in Eq. 6 (Lagergren, 1898):

$$
\log \left(q_{e}-q_{t}\right)=\log q_{e}-\left(\frac{k_{1}}{2.303}\right) t
$$

where:

$k_{1}=$ rate constant of the pseudo-first-order adsorption process $\left(\mathrm{min}^{-1}\right)$,

$q_{e}=$ amount of material adsorbed per unit mass of adsorbent at equilibrium (mg),

$q_{t}=$ amount of material adsorbed per unit mass of adsorbent at time $t(\mathrm{mg})$

The pseudo-second-order model used is as provided in Eq. 7 (Ho and Mckay 1998):

$$
\frac{t}{q_{t}}=\frac{1}{k_{2} q_{e}^{2}}-\frac{1}{q_{e}} t
$$

where:

$k_{2}=$ rate constant of the pseudo-second-order adsorption process $\left(\mathrm{g} \cdot \mathrm{mg}^{-1} \cdot \mathrm{min}^{-1}\right)$,

$q_{e}=$ amount of material adsorbed per unit mass of adsorbent at equilibrium (mg)

$q_{t}=$ amount of material adsorbed per unit mass of adsorbent at time $t(\mathrm{mg})$.

The value of $k_{2}$ was calculated from the plot of $t \cdot q_{e}^{-1}$ versus $t$, where $\left(k_{2}^{-1} \cdot q_{e}^{-1}\right)$ was the intercept and $q_{e}^{-1}$ was the slope of the plot.

\section{Adsorption isotherms}

Langmuir and Freundlich isotherms were used to determine the adsorption mechanism of 3-methyl-4-nitrophenol on the surface of CS-based adsorbents. The Langmuir isotherm model used was described by Eq. 8 .

$$
\frac{1}{q_{e}}=\frac{1}{K_{L} q_{m}} \frac{1}{C_{e}}+\frac{1}{q_{m}}
$$

where:

$q_{e}=$ equilibrium uptake of the material $\left(\mathrm{mg} \cdot \mathrm{g}^{-1}\right)$

$q_{m}=$ maximum adsorption capacity $\left(\mathrm{mg} \cdot \mathrm{g}^{-1}\right)$

$K_{L}=$ Langmuir isotherm constant related to the adsorption energy

$C_{e}=$ equilibrium (final) concentration of material in the solution $\left(\mathrm{mg} \cdot \mathrm{L}^{-1}\right)$.

$K_{L}$ and $q_{m}$ were calculated from the linear plot of $C_{e} \cdot q_{e}^{-1}$ vs. $C_{e}$ when using Eq. 8 where $q_{m}{ }^{-1}$ is the gradient of the straight line, $K_{L}^{-1} \cdot q_{m}{ }^{-1}$ is the y-intercept or from the linear plot of $q_{e}^{-1}$ vs. $C_{e}^{-1}$ when using Eq. 8, where $K_{L}^{-1} \cdot q_{m}{ }^{-1}$ is the gradient of the straight line and $q_{m}^{-1}$ is the y-intercept (Li et al., 2009). $K_{L}$, which is also known as the association constant, expressed in $\mathrm{L} \cdot \mathrm{mg}^{-1}$, was used to determine the affinity of the adsorbate on the surface of the adsorbent.

The dimensionless parameter $R_{L}$ was calculated using Eq. 9. This parameter can be used to predict the adsorption efficiency of the adsorbent. The process is irreversible if $R_{L}=0$, favourable if $R_{L}<1$, linear if $R_{L}=1$ and unfavourable if $R_{L}>1$.

$$
R_{L}=\frac{1}{1+K_{L} C_{0}}
$$

where:

$K_{L}$ was the Langmuir isotherm constant determined in Eq. 8 and $C_{0}$ was the initial concentration of the adsorbate (Salim and Munekage, 2009)

The Langmuir isotherm model used was derived from Eq. 10:

$$
\log q_{e}=\log K_{f}+\frac{1}{n} \log C_{e}
$$

where:

$q_{e}$ was the equilibrium solid phase material concentration per gram of adsorbent $\left(\mathrm{mg}^{\mathrm{g}} \mathrm{g}^{-1}\right)$

$C_{e}$ was the equilibrium material concentration in the bulk phase $\left(\mathrm{mg} \cdot \mathrm{L}^{-1}\right)$

$K_{f}$ was the Freundlich isotherm constant $\left(\mathrm{mg} \mathrm{g}^{-1}\right)$

$n$ was the adsorption intensity

The values of $K_{f}$ and $n$ were obtained from the $y$-intercept and the slope of the plot $\left(\log q_{e}\right.$ vs. $\left.\log C_{e}\right)$ of linearized Eq. 10. 


\section{Mechanism of adsorption}

The D-R model given by Kumar et al. (2010) was used to determine the mechanism of adsorption of 3-methyl-4nitrophenol onto CS-based nanofibres. The equations used to make the linear plots for the model are as follows:

$$
\ln \left(q_{e}\right)=\ln \left(q_{m}\right)-\beta \varepsilon^{2}
$$

Where $\varepsilon$ can be correlated by:

$$
\ln \left(q_{e}\right)=\ln \left(q_{m}\right)-8 \varepsilon^{2}
$$

where $R$ is the gas constant $\left(8.314 \mathrm{~J} \cdot \mathrm{mol}^{-1} \cdot \mathrm{K}^{-1}\right)$ and $T$ is the absolute temperature in Kelvin. The equilibrium concentrations of the phenols were used to determine the values of $\varepsilon$. The slope of the plot of $\varepsilon^{2}$ vs $\ln q_{e}$ was used to determine the values of $\beta$ which are presented in Table 4 . The constant $\beta$ is related to the mean free adsorption energy, $E\left(\mathrm{~kJ} \cdot \mathrm{mol}^{-1}\right)$ ( Masheane et al., 2016)denoted as $\mathrm{Al}$ in the nanocomposites.

$$
\varepsilon=R T \ln \left(1+\frac{1}{C e}\right)
$$

\section{Reusability of the nanofibres}

The CS-based nanofibres were tested for the reusability capabilities. To do this, the nanofibres were purified and dried after every cycle using ethanol and $\mathrm{NaOH}$. The nanofibres were dispersed and stirred in ethanol for $4 \mathrm{~h}$. The pre-washed nanofibres in ethanol were filtered and re-washed with $0.2 \mathrm{M}$ $\mathrm{NaOH}$ for desorption of the remaining nitrophenols. Drying of the nanofibres was done at $40^{\circ} \mathrm{C}$ for $24 \mathrm{~h}$. The subsequent nanofibres were then used for re-adsorption studies by evaluating recovery of the $100 \mathrm{mg} \cdot \mathrm{L}^{-1}$ nitrophenol indicator compound.

\section{RESULTS AND DISCUSSION}

\section{Morphology of the nanofibres}

The CS powder used in this study produced a highly viscous solution when added to the glacial acetic acid, which could not be ejected out of the spinneret during electrospinning. To reduce the viscosity of the solution while maintaining an electrospinnable solution, CS was blended with polyacrylamide (PAA). PAA is a long molecular chain polymer which assisted in the entanglement and intertwinement of the CS polymer during electrospinning. Polyethylene glycol (PEG) and polyisoprene (PIP) were added to the electrospinning solution of CS to reduce the surface tension of the resulting solution and to reduce the swelling potential of the produced nanofibres, respectively. Uniform non-beaded nanofibres were obtained with $3 \%$ blended polymer concentration with the following ratios: CS:PA at 78:22, 5\% PEG and $80 \%$ PIP relative to CS. PIP not only reduced the swelling behaviour of CS but also improved the aesthetic appearance of the nanofibres. The uniform and non-beaded nanofibres were obtained at the electrospinning polymer flow rate of $0.7 \mathrm{~mL} \cdot \mathrm{h}^{-1}$, a distance of 21 $\mathrm{cm}$ between the aluminium foil and the tip of the needle, and a voltage of $24 \mathrm{kV}$ at room temperature.

Both cross-linked and non-crosslinked nanofibres were characterized by uniform woven nanofibre mats. The integrity of the nanofibres was maintained after cross-linking
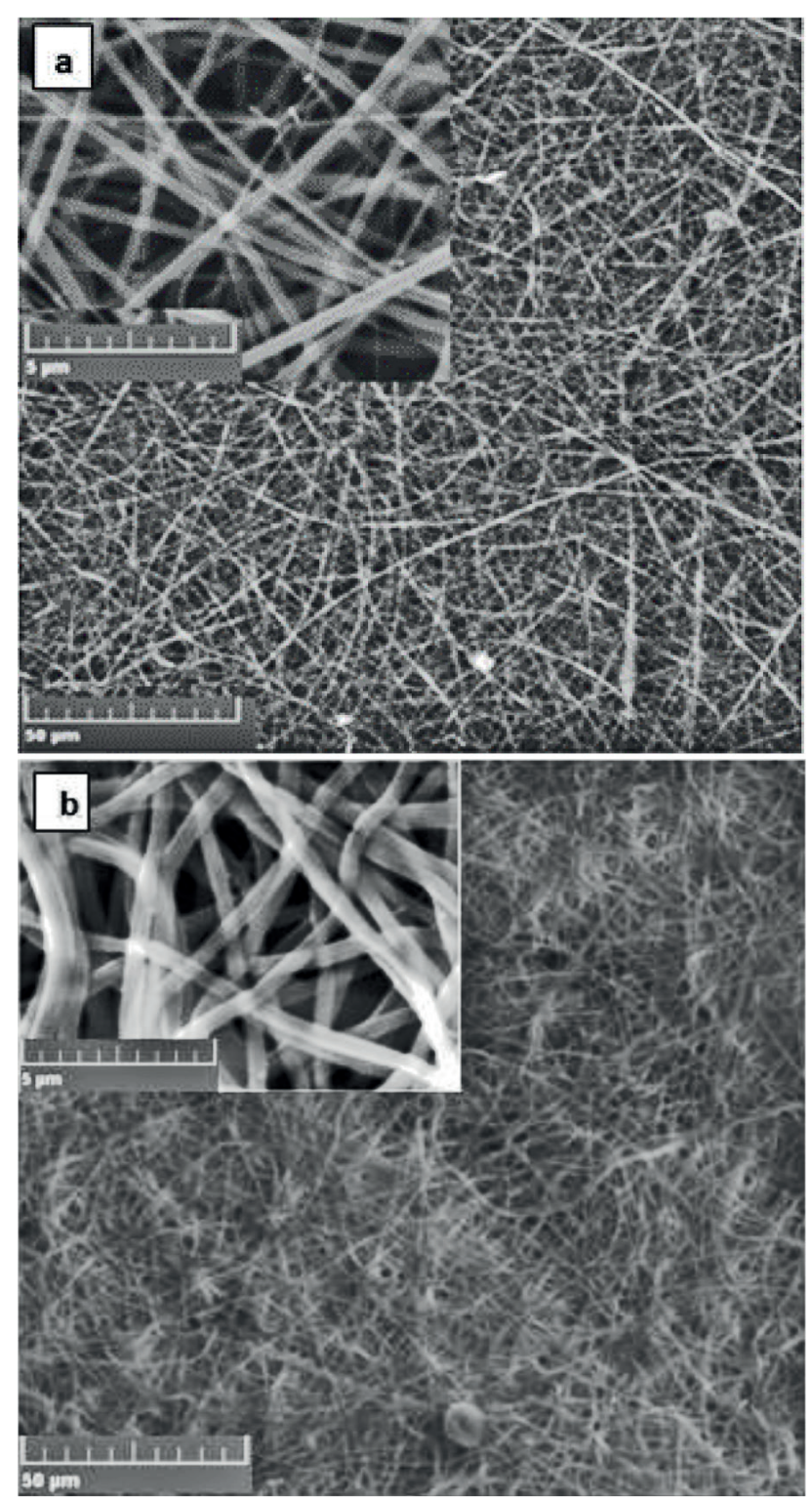

Figure 1

SEM images of the CS-based nanofibres: (a) Noncross-linked nanofibres and (b) cross-linked nanofibres

with GLA. There was no structural deformation observed. However, the size of the cross-linked nanofibres increased from $471 \pm 139 \mathrm{~nm}$ (Fig. 1a) to $527 \pm 284 \mathrm{~nm}$ (Fig. 1b). This was ascribed to the swelling behaviour of the CS-based nanofibres due to absorption of the moisture during cross-linking.

\section{Swelling tests}

The swelling behaviour of the CS-based nanofibres is presented in Fig. 2. The swelling rate of all the nanofibres with different degree of cross-linking was found to be high in the first 20 $\mathrm{min}$. The swelling rate decreased after $20 \mathrm{~min}$ until equilibrium was reached at $90 \mathrm{~min}$. When CS was cross-linked with GLA at the CS:GLA ratio of 1:0.25, the equilibrium swelling was found to be $122 \%$. When CS was blended with PIP at CS:PIP ratio of 1:0.8 and cross-linked with GLA at CS:GLA ratio of $1: 0.25$, the equilibrium swelling was found to be $60 \%$. When 
CS was cross-linked with GLA at the CS:GLA ratio of 1:1, the equilibrium swelling was found to be $81 \%$. When CS was blended with PIP at CS:PIP ratio of 1:0.8 and cross-linked with GLA at CS:GLA ratio of 1:1, the equilibrium swelling was found to be $38 \%$. It was observed that blending CS with PIP and crosslinking with GLA reduced the swelling behaviour of CS-based nanofibres by $50 \%$ relative to unblended nanofibres, with respect to specific cross-linking. This reduction in water uptake of CS-based nanofibres on the addition of PIP can be related to the decrease in hydrophilic groups which are the main sources of water uptake (Xie and Wang, 2010).

\section{Adsorption of 3-methyl-4-nitrophenol using CS-based nanofibres}

This study reports on the adsorption of 3-methyl-4nitrophenol using CS-based nanofibres. This study was conducted in conjunction with the adsorption of 2-chlorophenol using CS-based nanofibres as well as cyclodextrin/cellulose acetate nanofibres (Nthunya et al. 2017; Nthunya et al. 2017). The latter was done to determine the removal efficiency of the non-branched phenolic compounds as well as the ability of the cavity-rich materials for the removal of phenols from water. Due to length limitations, the latter results are not presented here. Thus, the parameters that affect the adsorption of 3-methyl-4-nitrophenol on CS-based nanofibres are presented below.

\section{The effect of $\mathrm{pH}$}

The adsorption of 3-methyl-4-nitrophenol was conducted at a $\mathrm{pH}$ range of 5-11. The acceptable $\mathrm{pH}$ of drinking water given in the WHO guidelines for drinking water quality is in the range of 6.5-8.5 (WHO, 1996). It was, therefore, necessary to determine the optimum $\mathrm{pH}$ for the adsorption of the 3-methyl4-nitrophenol at the acceptable limit of $\mathrm{pH}$ in drinking water. Figure 3 presents the effect of $\mathrm{pH}$ on the adsorption of 3-methyl-4-nitrophenol using CS-based nanofibres. The adsorption efficiency was found to range between 64 and $68 \%$ at $\mathrm{pH} 5-7$, with the highest efficiency observed for the adsorptions done using CS:GLA (1:0.25). The low adsorption efficiencies were offset by increasing the amount of nanofibres used as adsorbents (see forthcoming sections). The adsorption efficiency was higher at the cross-linking ratio of 1:0.25 CS:GLA because fewer functional groups responsible for adsorption were used for cross-linking as compared to the ratio of 1:0.5 and 1:1 where more functional groups were utilized for cross-linking. The gradual significant decrease in adsorption efficiency was observed at $\mathrm{pH}>8$ (Fig. 3).

The changes in adsorption efficiency of the CS-based nanofibres for adsorption of 3-methyl-4-nitrophenol were due to changes in speciation of phenols (including nitrophenols) at different $\mathrm{pH}$ values. Phenols are known to exist as negative phenolate ions at $\mathrm{pH}$ values greater than their $\mathrm{pKa}$ values (Li et al., 2009). The formed phenolates have high electron delocalization than that of their corresponding phenols (Li et al., 2009). This electron delocalization stabilizes the phenolate ions hence decreasing their electrostatic interactions with the active surface of CS-based nanofibrous adsorbents (Gholizadeh et al., 2013). The theoretical pKa value of 3-methyl4-nitrophenol is known to be 7.41 (Robinson and Stokes, 2002). At $\mathrm{pH}$ values higher than 7.41 , the phenols form conjugate phenolate ions which decreased their adsorption efficiency on the surface of CS-based nanofibres. Therefore, $\mathrm{pH} 7$ was chosen

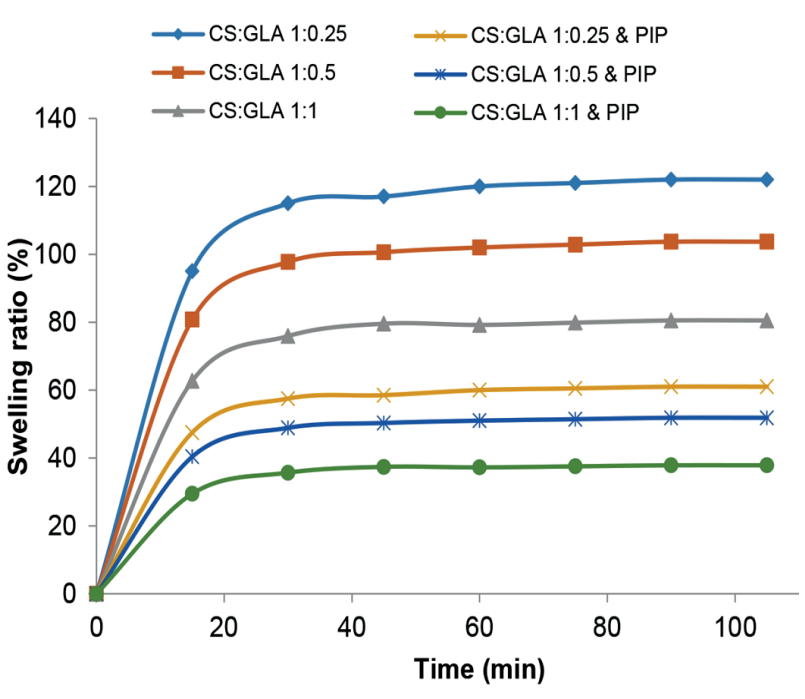

Figure 2

The swelling behaviour of CS-based nanofibres

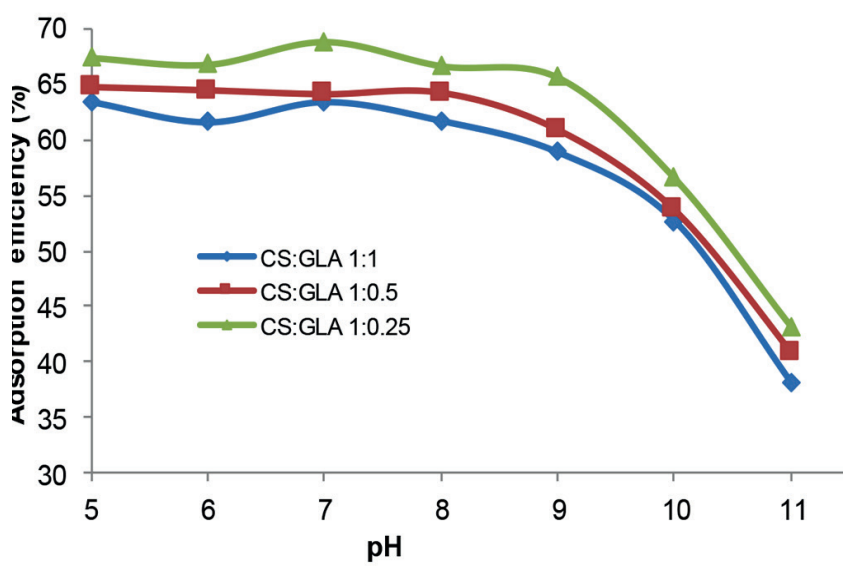

Figure 3

The effect of $\mathrm{pH}$ on the adsorption of 3-methyl-4-nitrophenol (100 mg. $\mathrm{L}^{-1}$ in water) using CS-based nanofibres cross-linked with different ratios of GLA

for subsequent adsorption studies since it is the acceptable $\mathrm{pH}$ of the potable water and was found to show better adsorption efficiency for 3-methyl-4-nitrophenol.

\section{The effect of adsorbent dose}

The effect of the amount (dose) of CS-based nanofibres on the adsorption of 3-methyl-4-nitrophenol was investigated. Figure 4 depicts the changes in adsorption of 3-methyl-4nitrophenol as the dose of CS-based nanofibres was varied. It was observed that the adsorption of 3-methyl-4-nitrophenol was rapid as the dose of nanofibres was increased from $50 \mathrm{mg}$ to $200 \mathrm{mg}$. The adsorption efficiency was found to increase gradually from $250 \mathrm{mg}$ of CS-based nanofibres until no observable improvement was reached at $350 \mathrm{mg}$ (Fig. 4). The rapid change in adsorption efficiency with increase in adsorbent dose was associated with the increased number of adsorption sites, which facilitate more uptake of the pollutants from the water as the dose of nanofibres is increased. 
The adsorption efficiency increased gradually to a steady state (equilibrium) at the aforementioned ranges of adsorbent dose, due to inaccessibility of adsorption sites as the adsorbent active sites became saturated. Therefore, $350 \mathrm{mg}$ was found to be the minimum dose of CS-based nanofibres that removed a noticeable amount of 3-methyl-4-nitrophenol for $25 \mathrm{~mL}$ of aqueous solution used. As a result, $350 \mathrm{mg}$ of CS-based nanofibres was used in the subsequent adsorption experiments.

\section{The effect of contact time}

The effect of contact time for the adsorption of 3-methyl-4nitrophenol onto CS-based nanofibres was investigated (Fig. 5). The adsorption of 3-methyl-4-nitrophenol was found to increase rapidly in the first $30 \mathrm{~min}$ of stirring (Fig. 5). Thereafter, the adsorption efficiency increased at a slower rate from $60 \mathrm{~min}$ until equilibrium was attained at 150 min where $84 \%$ efficiency was observed. The rapid rate of adsorption could be explained by the availability of adsorption sites in abundance at the beginning of adsorption. As the stirring was increased, the adsorption sites on the surface of the CS-based nanofibres were depleted until a saturation point (Yan and Quan, 2009). The stirring time of 150 min was then chosen as the optimum time for adsorption of 3-methyl-4-nitrophenol on CS-based nanofibres.

\section{The effect of initial concentration of 3-methyl-4- nitrophenol}

Figure 6 illustrates the changing trend of adsorption efficiency of 3-methyl-4-nitrophenol on the CS-based nanofibres as the initial concentration of the adsorbate was changed. The adsorption efficiency did not change significantly at the initial concentration range of $40-60 \mathrm{mg} \cdot \mathrm{L}^{-1}$. Beyond the stipulated initial concentrations of 3-methyl-4-nitrophenol (60 mg. $\mathrm{L}^{-1}$ of nitrophenol), the adsorption efficiency was observed to decrease significantly. The increase in adsorbate concentration increased the number of molecules of adsorbate (i.e., 3-methyl4-nitrophenol) to be adsorbed on the surface of the adsorbent (Moyo et al., 2012). The increase in number of molecules increased the competition of adsorbates for the surface of the adsorbent. Therefore, the CS-based nanofibre sites were saturated when exposed to higher concentration levels, resulting in a reduced adsorption efficiency for the 3-methyl4-nitrophenol (Surikumaran et al., 2014)4-dichlorophenol (2,4-DCP.

\section{Reusability of the CS-based nanofibres}

The CS-based nanofibres were recycled 5 times to determine their reusability for the adsorption of 3-methyl-4-nitrophenol. The adsorptions were conducted at the following optimized conditions: $\mathrm{pH} 7,350 \mathrm{mg}$ of CS-based nanofibres, agitation/ contact time of $150 \mathrm{~min}$. Figure 7 presents the results for the ability of the CS-based nanofibres to remove 3-methyl4-nitrophenol from the water after 5 repeated runs. Ethanol followed by $\mathrm{NaOH}$ was used for desorption since phenols are very soluble in ethanol and have weak electrostatic interaction with the negatively charged adsorbents at a $\mathrm{pH}$ higher than their pKa values (Dada et al., 2012). The adsorption efficiency of the CS-based nanofibres was observed to decrease by $12 \pm 6 \%$ for all cycles. These results showed that CS-based nanofibres have moderate regeneration abilities where high adsorption efficiencies were obtained in the first 2 cycles and poor adsorption efficiencies beyond 3 cycles of repeatability.

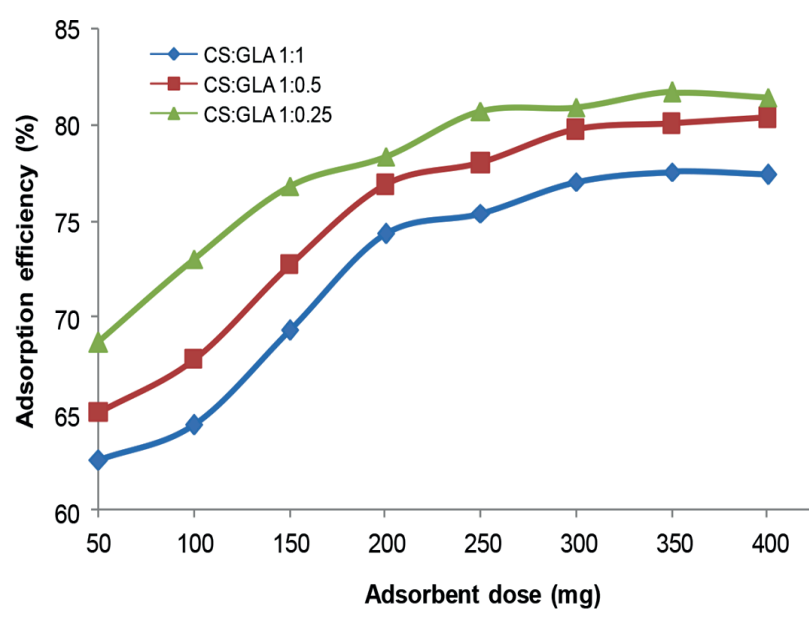

Figure 4

The effect of adsorbent dose on adsorption of 3-methyl-4-nitrophenol (100 mg. $\mathrm{L}^{-1}$ in water) using CS-based nanofibres cross-linked with different ratios of GLA. The stirring time was kept constant at $50 \mathrm{~min}$.

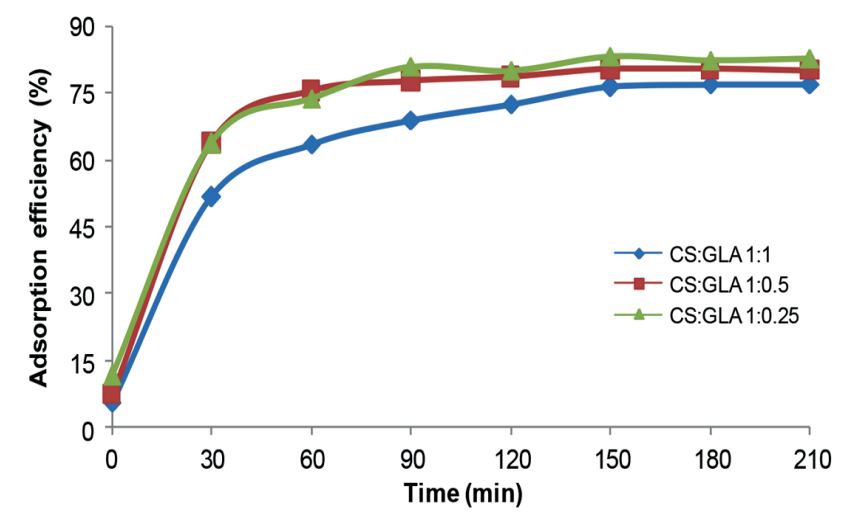

Figure 5

The effect of contact time on adsorption of 3-methyl-4-nitrophenol (100 mg. $\mathrm{L}^{-1}$ in water) using CS-based nanofibres cross-linked with different ratios of $G L A$

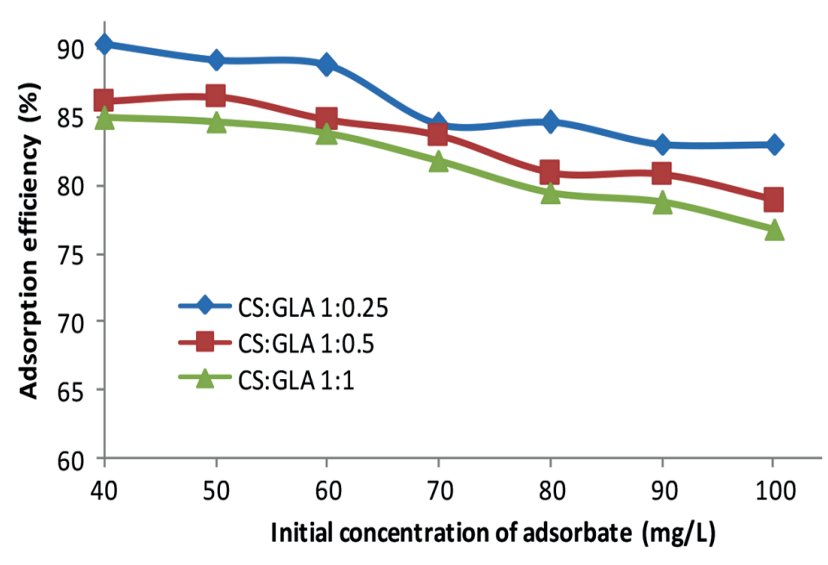

Figure 6

The effect of initial concentration $\left(40-100 \mathrm{mg} \cdot \mathrm{L}^{-1}\right)$ of 3-methyl-4-nitrophenol on adsorption efficiency of CS-based nanofibres cross-linked with different ratios of GLA. The stirring time was kept constant at $150 \mathrm{~min}$. 


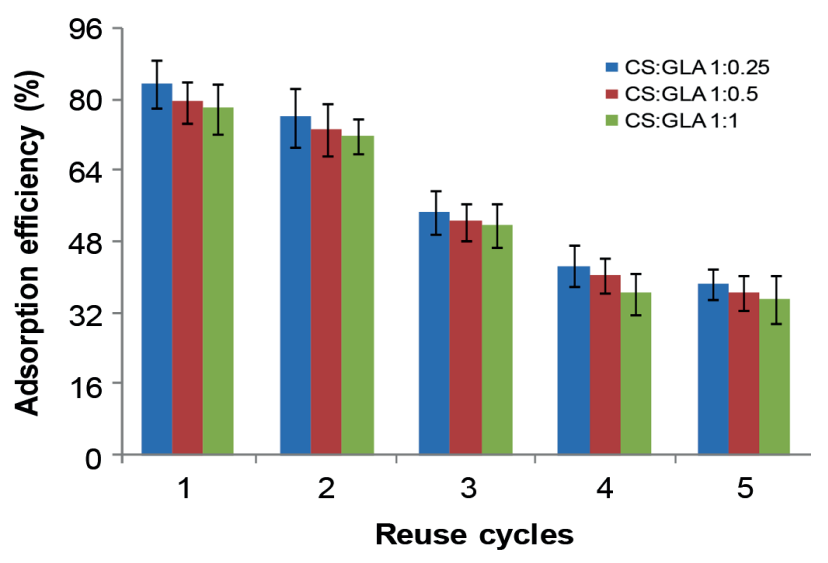

Figure 7

The relationship between reusability of the CS-based nanofibres and the adsorption efficiency

\section{Adsorption kinetics}

The rates of adsorption of 3-methyl-4-nitrophenol using the CS-based nanofibres were determined using pseudo-firstorder kinetics and pseudo-second order kinetic models. The linearized graphs of pseudo-first-order kinetics and pseudosecond-order kinetics are illustrated in Figs 8 and 9.

The $R^{2}$ values of the pseudo-first order and pseudo-second order kinetics were compared to determine the kinetics followed by adsorption of 3-methyl-4-nitrophenol onto CS-based nanofibres (Table 1).

The $R^{2}$ values of the pseudo-first-order kinetics were found to be lower than the $R^{2}$ values of the pseudo-second-order kinetics for all the nanofibres. Therefore, the adsorption of 3-methyl-4-nitrophenol on CS-based nanofibres followed pseudo-second-order kinetics. This implies that the adsorption of 3-methyl-4-nitrophenol on CS-based nanofibres is highly efficient. However, the final conclusion should be made based on the rate constants for the adsorption of the 3-methyl-4nitrophenol on the aforementioned nanofibres.

TABLE 1

The correlation coefficient values for pseudo-first-order and pseudo-second-order kinetics on adsorption of 3-methyl4-nitrophenol using CS-based nanofibres cross-linked with different ratios of GLA.

\begin{tabular}{|l|l|c|}
\hline Adsorbent & $\boldsymbol{R}^{\mathbf{2}}{ }_{\text {st order }}$ & $\boldsymbol{R}^{\mathbf{2}}{ }_{\text {} \text { nd order }}$ \\
\hline CS:GLA 1:1 & 0.979 & 0.994 \\
\hline CS:GLA 1:0.5 & 0.945 & 0.998 \\
\hline CS:GLA 1:0.25 & 0.896 & 0.998 \\
\hline
\end{tabular}

TABLE 2

The rate constants of the pseudo-first-order and pseudosecond-order kinetics

\begin{tabular}{|l|l|l|}
\hline Adsorbent & $\begin{array}{l}\boldsymbol{k}_{\mathbf{1}} \text { for first-order } \\
\text { kinetics }\left(\mathbf{m i n}^{-1}\right)\end{array}$ & $\begin{array}{l}\boldsymbol{k}_{\mathbf{2}} \text { for second- } \\
\text { order } \mathbf{~} \text { inetics }_{\left(\mathbf{g} \cdot \mathbf{m g}^{-1} \cdot \mathbf{m i n}^{-1}\right)}\end{array}$ \\
\hline CS:GLA 1:1 & -0.0235 & 0.2444 \\
\hline CS:GLA 1:0.5 & -0.0256 & 0.2384 \\
\hline CS:GLA 1:0.25 & -0.0239 & 0.2439 \\
\hline
\end{tabular}

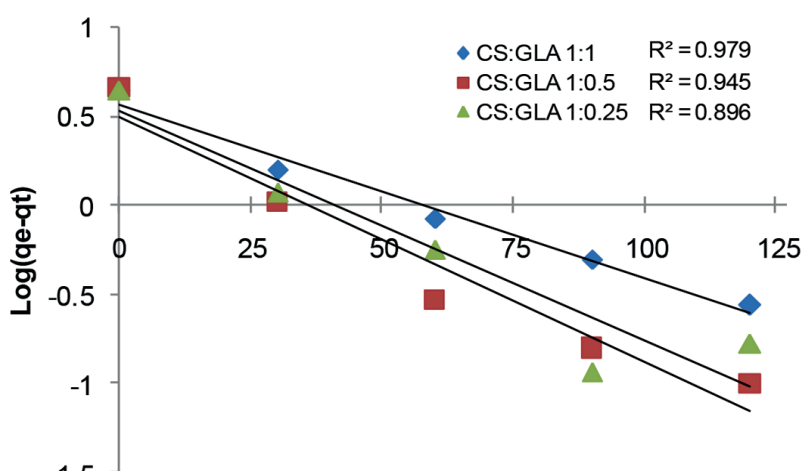

Time (min)

Figure 8

The linearized pseudo-first-order kinetics graphs for adsorption of 3-methyl-4-nitrophenol using CS-based nanofibres with different degree of cross-linking

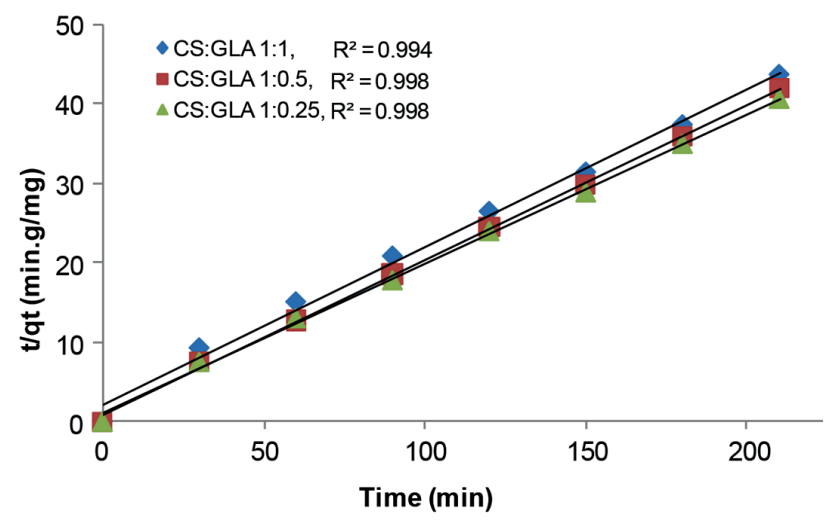

Figure 9

The linearized pseudo-second order kinetics graphs for adsorption of 3-methyl-4-nitrophenol using CS-based nanofibres with different degree of cross-linking

The rate constant values for both the pseudo-first-order kinetics and pseudo-second-order kinetics are presented in Table 2. The rate constants of the pseudo-first-order kinetics for the adsorption carried out using CS-based nanofibres at the following CS:GLA cross-linking ratios of 1:1, 1:0.5 and 1:0.25 were found to be $-0.0235 \mathrm{~min}^{-1},-0.0256 \mathrm{~min}^{-1}$ and $-0.02439 \mathrm{~min}^{-1}$, respectively. The rate constants of pseudosecond-order kinetics for the adsorption carried out at the following CS:GLA cross-linking ratios of 1:1, 1:0.5 and 1:0.25 were found to be $0.2444 \mathrm{~g} \cdot \mathrm{mg}^{-1} \cdot \mathrm{min}^{-1}, 0.2384 \mathrm{~g} \cdot \mathrm{mg}^{-1} \cdot \mathrm{min}^{-1}$, and $0.2439 \mathrm{~g} \cdot \mathrm{mg}^{-1} \cdot \mathrm{min}^{-1}$, respectively. Since the rate constants for the pseudo-second-order kinetics were greater than those of the pseudo-first order kinetics, this suggested that the rate of adsorption favoured pseudo-second order kinetics. This agreed with the $R^{2}$ values observed which showed that adsorption of 3-methyl-4-nitrophenol preferentially demonstrated pseudosecond order kinetics over pseudo-first-order kinetics.

\section{Adsorption isotherms}

Langmuir and Freundlich isotherms were used to determine the adsorption mechanism of 3-methyl-4-nitrophenol on the surface of the CS-based adsorbents. The linearized Langmuir and Freundlich isotherms which were used to determine the constants and factors are presented in Figs 10 and 11. 
The Langmuir constants were found to be $-0.0216 \mathrm{mg} \cdot \mathrm{g}^{-1}$, $-0.0230 \mathrm{mg} \cdot \mathrm{g}^{-1}$ and $-0.0283 \mathrm{mg} \cdot \mathrm{g}^{-1}$ with CS-based nanofibres at the following ratios of cross-linking: CS:GLA = 1:1, 1:0.5 and 1:1.025, respectively (Table 3). The Freundlich isotherm constants were found to be $737 \mathrm{mg} \cdot \mathrm{g}^{-1}, 508 \mathrm{mg} \cdot \mathrm{g}^{-1}$ and 1729 $\mathrm{mg} \cdot \mathrm{g}^{-1}$ with CS-based nanofibres at CS:GLA $=1: 1,1: 0.5$ and 1:0.25, respectively (Table 3 ).

The dimensional factors of the Langmuir isotherm for the adsorption carried out using CS-based nanofibres were less than 1 . This suggested that the adsorption did not follow the Langmuir isotherm. However, the final conclusion could be drawn based on the $R^{2}$ values. The $n^{-1}$ values of the Freundlich isotherms were found to be $5.380,2.706$, and 3.238 for the adsorption carried out with CS-based nanofibres at 1:1, 1:0.5 and 1:0.25 ratios of cross-linking. It was thus concluded that the adsorption of 3-methyl-4-nitrophenol onto CS-based nanofibres followed the Freundlich isotherm and the molecules formed multiple layers on the surface of the CS-based nanofibrous adsorbent (Dada et al., 2012).

The $R^{2}$ values obtained from the plots of the linearized Langmuir and Freundlich isotherms were used to determine the adsorption mechanism of 3-methyl-4-nitrophenol on the surface of the CS-based nanofibres. When comparing the $R^{2}$ values of both isotherms, it was found that the better correlation was with the Freundlich isotherm since the $R^{2}$ values for the Freundlich isotherm were greater than those for the Langmuir isotherm for all adsorbents. Therefore, the adsorption of 3-methyl-4nitrophenol followed the Freundlich isotherm, suggesting a heterogeneous adsorption of 3-methyl-4-nitrophenol forming more than one layer on the surface of the nanofibres.

\section{Mechanism of adsorption}

The D-R model was used to evaluate the nature of the interaction between 3-methyl-4-nitrophenol and CS-based nanofibres. Figure 12 is the plot of the D-R model for the adsorption of 3-methyl-4nitrophenol on CS-based nanofibres. The adsorption mean-freeenergy $E$ was used for this purpose. $E$ is the free energy required to transfer $1 \mathrm{~mol}$ of the adsorbate from the solution to the surface of the adsorbent (Kumar et al., 2010). The magnitude of $E$ is therefore used to estimate whether the interaction between the adsorbate and the adsorbent is physical or chemical. The mean free energy for adsorption of 3-methyl-4-nitrophenol on CS nanofibres crosslinked with GLA at the ratios of 1:1, 1:0.5, 1:0.25 were found to be $60.5,59.3$ and $57.6 \mathrm{~kJ} \cdot \mathrm{mol}^{-1}$, respectively. These values indicated that the mechanism of adsorption was via the chemical interaction of 3-methyl-4-nitrophenol with the adsorbent; hence adsorption was chemisorption.

\section{CONCLUSION}

CS-based nanofibres were successfully synthesized using an electrospinning technique after a careful selection of reactants and reaction parameters. The CS-based nanofibres were

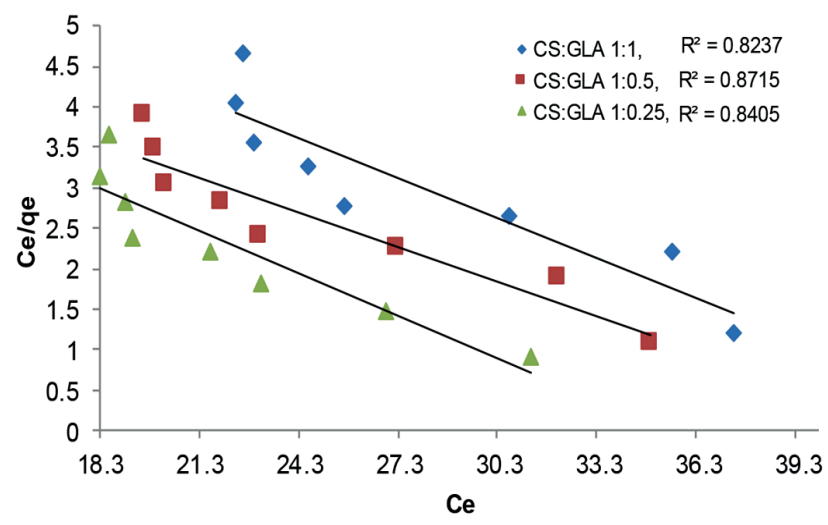

Figure 10

The Langmuir isotherm for adsorption of 3-methyl-4-nitrophenol using CS-based nanofibres with different degrees of cross-linking

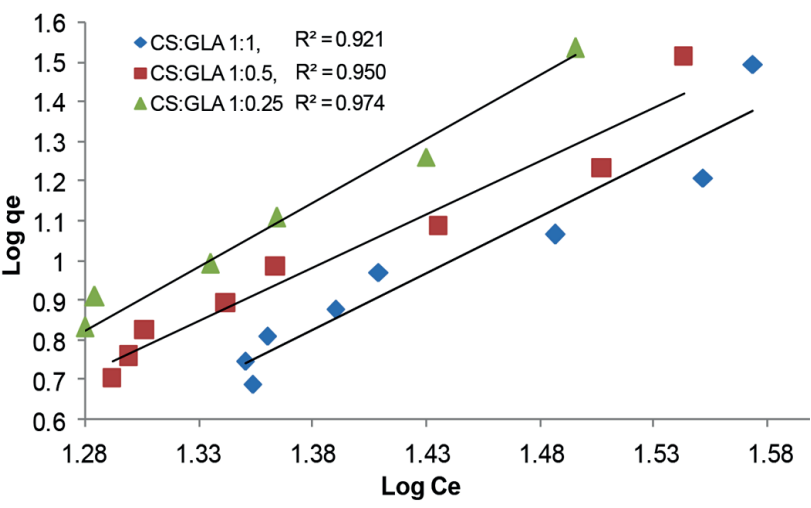

Figure 11

The Freundlich isotherm for adsorption of 3-methyl-4-nitrophenol using CS-based nanofibres with different degrees of cross-linking

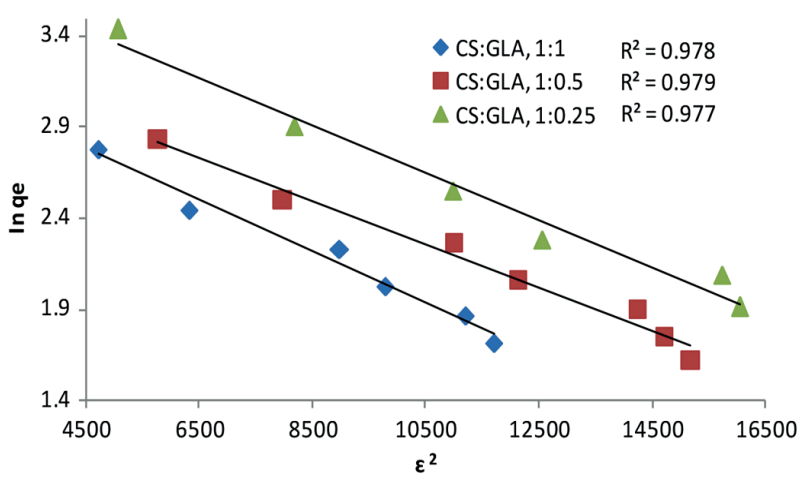

Figure 12

D-R plot for the adsorption of 3-methyl-4-nitrophenol on CS-based nanofibres

TABLE 3

The Langmuir and Freundlich constants, the Langmuir dimensional $\left(R_{L}\right)$ factor, the Freundlich heterogeneity factor $\left(n^{-1}\right)$ and the correlation coefficient $\left(R^{2}\right)$ values of the Langmuir and Freundlich isotherm models

\begin{tabular}{|l|l|c|c|c|c|c|}
\hline Adsorbent & $\boldsymbol{K}_{\mathbf{L}}\left(\mathbf{m g} \cdot \mathbf{g}^{-1}\right)$ & $\boldsymbol{K}_{\boldsymbol{F}}\left(\mathbf{m g} \cdot \mathbf{g}^{-1}\right)$ & $\boldsymbol{R}_{\mathbf{L}}$ & $\boldsymbol{n}^{-1}$ & $\boldsymbol{R}_{\mathbf{L}}{ }^{2}$ & $\boldsymbol{R}_{\mathrm{F}}{ }^{2}$ \\
\hline CS:GLA 1:1 & -0.0216 & 737 & -0866 & 5.380 & 0.823 & 0.921 \\
\hline CS:GLA 1:0.5 & -0.0230 & 508 & -0.768 & 2.706 & 0.871 & 0.950 \\
\hline CS:GLA 1:0.25 & -0.0283 & 1729 & -0.548 & 3.238 & 0.840 & 0.974 \\
\hline
\end{tabular}




\begin{tabular}{|l|c|c|}
\hline \multicolumn{3}{|c|}{$\begin{array}{c}\text { TABLE 4 } \\
\text { Parameters of D-R model for adsorption of 3-methyl-4- } \\
\text { nitrophenol on CS-based nanofibres }\end{array}$} \\
\hline Material & $\beta\left(1 \cdot 10^{-4}\right)$ & $E\left(\mathbf{k J}^{\left.-\mathrm{mol}^{-1}\right)}\right.$ \\
\hline CS:GLA, $1: 1$ & 1.37 & 60.5 \\
\hline CS:GLA, 1:0.5 & 1.42 & 59.3 \\
\hline CS:GLA, 1:0.25 & 1.51 & 57.6 \\
\hline
\end{tabular}

found to remove up to $90 \%$ of 3-methyl-4-nitrophenol at the optimum $\mathrm{pH}$ of 5-7, an adsorbent dose of $350 \mathrm{mg}$, and $150 \mathrm{~min}$ contact time, in the first cycle of adsorption. The adsorption efficiency not only decreased in the second to last adsorption cycles but also increased with an increase in the degree of cross-linking. This was associated with the loss of functional groups that were used up as crosslinking sites. CS was blended with PAA, PEG and PIP to enhance its electrospinnability, reduce its surface tension, improve the morphology of the nanofibres and reduce their swelling capability. The adsorption of 3-methyl-4-nitrophenol onto CS-based nanofibres fitted pseudo-second-order kinetics well and the rate constants were found to be $0.2444 \mathrm{~g} \cdot \mathrm{mg}^{-1} \cdot \mathrm{min}^{-1}, 0.2384 \mathrm{~g} \cdot \mathrm{mg}^{-1} \cdot \mathrm{min}^{-1}$ and 0.2439 $\mathrm{g} \cdot \mathrm{mg}^{-1} \cdot \mathrm{min}^{-1}$ on CS-based nanofibres cross-linked with GLA at the following ratios 1:1, 1:0.5 and 1:0.25. The adsorption of 3-methyl-4-nitrophenol onto CS-based nanofibres was found to follow the Freundlich isotherm. This indicated that the molecules of 3-methyl-4-nitrophenol formed several layers on the surface of the nanofibres. The mechanism of interaction between 3-methyl-4-nitrophenol and the CS-based nanofibres was chemisorption; hence reusability studies indicated that there was a gradual decrease of adsorption efficiency of 3-methyl-4-nitrophenol from one cycle of adsorption to another. The high removal efficiency of 3-methyl-4-nitrophenol which was also observed in a parallel study conducted on 2-chlorophenol demonstrated the potential of the CS-based nanofibres in the purification of water contaminated with phenolic compounds.

\section{ACKNOWLEDGEMENTS}

The authors would like to thank the National Research Foundation (NRF) Nanotechnology Flagship Project (Grant number (UID): 97823), the DST/Mintek Nanotechnology Innovation Centre-Water Research Node and the Water Research Commission (WRC) for funding this work.

\section{REFERENCES}

DADA AO, OLALEKAN AP, OLATUNYA AM and DADA O (2012)

Langmuir, Freundlich, Temkin and Dubinin - Radushkevich isotherms studies of equilibrium sorption of $\mathrm{Zn}^{2+}$ unto phosphoric acid modified rice husk. J. Appl. Chem. 3 (1) 38-45.

EL-ASHTOUKHY ESZ, EL-TAWEEL YA, ABDELWAHAB O and NASSEF EM (2013) Treatment of petrochemical wastewater containing phenolic compounds by electrocoagulation using a fixed bed electrochemical reactor. Int. J. Electrochem. Sci. 8 1534-1550.

GEIBLER A and SCHOLAR HF (1994) Gas chromatographic determination of phenol, methylphenols, chlorophenols, nitrophenols and nitroquinones in water. Water Res. 28 (10) 2047-2053. https://doi.org/10.1016/0043-1354(94)90014-0

GHOLIZADEH A, KERMANI M, GHOLAMI M and FARZADKIA M (2013) Kinetic and isotherm studies of adsorption and biosorption processes in the removal of phenolic compounds from aqueous solutions: comparative study. J. Environ. Health Sci. Eng. 11 (29) 1-10. https://doi.org/10.1186/2052-336X-11-29

HO YS and MCKAY G (1998) Sorption of dye from aqueous solution by peat. Chem. Eng. J. 70 115-124. https://doi.org/10.1016/ S0923-0467(98)00076-1

KUMAR NS, SUGUNA M, SUBBAIAH MV, REDDY AS, KUMAR NP and KRISHNAIAH A (2010) Adsorption of phenolic compounds from aqueous solutions onto chitosan-coated perlite beads as biosorbent. Ind. Eng. Chem. Res. 49 (19) 9238-9247. https://doi. org/10.1021/ie901171b

LAGERGREN S (1898) Zur theorie der sogenannten adsorption gel`ster stoffe, Kungliga Svenska Vetenskapsakademiens. Handlingar Band 24 1-13.

LI J, MENG X, HU C and DU J (2009) Adsorption of phenol, p-chlorophenol and p-nitrophenol onto functional chitosan. Bioresour. Technol. 100 1168-1173. https://doi.org/10.1016/j. biortech.2008.09.015

LIU J, ZHENG XJ and TANG KY (2013) Study on the gravimetric measurement of the swelling behaviors of polymer films. Rev. Adv. Mater. Sci. 33 (5) 452-458.

MASHEANE M, NTHUNYA L, MALINGA S, NXUMALO E, BARNARD T and MHLANGA S (2016) Antimicrobial properties of chitosan-alumina/f-MWCNT nanocomposites. J. Nanotechnol. 2016 1-8. https://doi.org/10.1155/2016/5404529

MASHEANE ML, NTHUNYA LN, MALINGA SP, NXUMALO EN, BARNARD T and MHLANGA SD (2016) Chitosan-based nanocomposites for de-nitrification of water. Phys. Chem. Earth 100 212-224. https://doi.org/10.1016/j.pce.2016.10.004

MICHAŁOWICZ J and DUDA W (2007) Phenols - Sources and toxicity. Pol. J. Environ. Stud. 16 (3) 347-362.

MOYO M, MUTARE E, CHIGONDO F and NYAMUNDA BC (2012) Removal of phenol from aqueous solution by adsorption on yeast, Saccharomyces cerevisiae. Int. J. Res. Rev. Appl. Sci. 11 (3) 486-494.

NIE X, LIU J, ZENG X and YUE D (2012) Rapid degradation of hexachlorobenzene by micron Ag/Fe bimetal particles. J. Environ. Sci. 24 1-18.

NTHUNYA LN, MASHEANE ML, MALINGA SP, BARNARD TG, NXUMALO EN, MAMBA BB and MHLANGA SD (2016) UV-assisted reduction of in situ electrospun antibacterial chitosanbased nanofibres for removal of bacteria from water. RSC Adv. 6 95936-95943. https://doi.org/10.1039/C6RA19472A

NTHUNYA LN, MASHEANE ML, MALINGA SP, NXUMALO EN, BARNARD TG, KAO M, TETANA, ZN and MHLANGA SD (2016) Greener approach to prepare electrospun antibacterial $\beta$-cyclodextrin/cellulose nanofibers for removal of bacteria from water. ACS Sustainable Chem. Eng. 5 153-160. https://doi. org/10.1021/acssuschemeng.6b01089

NTHUNYA LN, MASHEANE ML, MALINGA SP, NXUMALO EN, MAMBA BB and MHLANGA SD (2017) Determination of toxic metals in drinking water sources in the Chief Albert Luthuli Local Municipality in Mpumalanga, South Africa. Phys. Chem. Earth 100 94-100. https://doi.org/10.1016/j.pce.2017.04.006

NTHUNYA LN, MASHEANE ML, MALINGA SP, NXUMALO EN, MAMBA BB and MHLANGA SD (2017) Thermally and mechanically stable $\beta$-cyclodextrin/cellulose acetate nanofibers synthesized using an environmentally benign procedure. Int. J. Smart Nano Mater. 8 (1) 1-19. https://doi.org/10.1080/19475411.20 17.1289276

NTHUNYA LN, MASHEANE ML, MALINGA SP, NXUMALO EN and MHLANGA SD (2017) Environmentally benign chitosanbased nanofibres for potential use in water treatment. Cogent Chem. 3 1-17. https://doi.org/10.1080/23312009.2017.1357865

OLUJIMI OO, FATOKI OS, ODENDAAL JP and OKONKWO JO (2010) Endocrine disrupting chemicals (phenol and phthalates) in the South African environment: A need for more monitoring. Water SA 36 (5) 671-682. https://doi.org/10.4314/wsa.v36i5.62001

RAJARAM T and DAS A (2008) Water pollution by industrial effluents in India: Discharge scenarios and case for participatory ecosystem specific local regulation. Futures 40 (1) 56-69. https://doi. org/10.1016/j.futures.2007.06.002

RICHTER H, BENISH TG, MAZYAR OA, GREEN WH and HOWARD JB (2000) Formation of polycyclic aromatic hydrocarbons and their radicals in a nearly sooting premixed 
benzene flame. Proc. Combust. Inst. 28 (2) 2609-2618. https://doi. org/10.1016/S0082-0784(00)80679-7

ROBINSON RA and STOKES RH (2002) Electrolyte solutions ( $2^{\text {nd }}$ edn.).: Butterworth and Co., United Kingdom. 561 pp.

SALIM MD and MUNEKAGE Y (2009) Lead removal from aqueous solution using silica ceramic: Adsorption kinetics and equilibrium studies. Int. J. Chem. 1 (1) 23-30. https://doi.org/10.5539/ijc.vln1p23

SARTORI AV, KRAUSS TM, MARIA A, BAHIA C, GOMES A, YAMAZAKI A and OLIVEIRA RM (2012) Chlorophenols in tap water from wells and surface sources in Rio de Janeiro, Brazil method validation and analysis. Quim. Nova 35 (4) 814-817. https:// doi.org/10.1590/S0100-40422012000400029

SULEJ AM, POLKOWSKA Ż and NAMIEŚNIK J (2012) Contaminants in airport run-off water in the vicinities of two international airports in Poland. Pol. J. Environ. Stud. 21 (3) 725-739.

SUN K and LI ZH (2011) Preparations, properties and applications of chitosan based nanofibers fabricated by electrospinning. Express Polymer Lett. 5 (4) 342-361. https://doi.org/10.3144/ expresspolymlett.2011.34

SURIKUMARAN H, MOHAMAD S and SARIH NM (2014)

Molecular imprinted polymer of methacrylic acid functionalised $\beta$-cyclodextrin for selective removal of 2,4-dichlorophenol. Int. J. Mol. Sci. 15 6111-6136. https://doi.org/10.3390/ijms15046111

TELI SB, MOLINA S, SOTTO A, GARC E and ABAJO J (2013) Fouling resistant polysulfone - $\mathrm{PANI} / \mathrm{TiO}_{2}$ ultra filtration nanocomposite membranes. Ind. Eng. Chem. Res. 52 9470-9479. https://doi. org/10.1021/ie401037n

VENKATESAN J and KIM SK (2010) Chitosan composites for bone tissue engineering: an overview. Mar. Drugs 8 (8) 2252-2266. https://doi.org/10.3390/md8082252

WHO (2011) Acrylamide in drinking-water. Background document for development of WHO Guidelines for Drinking-Water Quality. URL: http://www.who.int/water_sanitation_health/dwq/chemicals/ acrylamide.pdf (Accessed 3 August 2016).

WHO (1996) Guidelines for drinking-water quality. Second edition. Volume 2. Health criteria and other supporting information. URL: http://www.who.int/water_sanitation_health/dwq/2edaddvol2a.pdf (Accessed 12 February 2016).

XIE YT and WANG AQ (2010) Preparation and swelling behaviour of chitosan-g-poly(acrylic acid)/muscovite suberabsorbent composite. Iran. Polym. J. 19 (2) 131-141.

YAN J and QUAN G (2009) Equilibrium and kinetic studies of phenol sorption by chitosan coated montmorillonite. J. Chil. Chem. Soc. $\mathbf{5 4}$ (1) 73-76. https://doi.org/10.4067/S0717-97072009000100017

ZHOU HY, ZHOU DJ, ZHANG WF, JIANG LJ, LI JB and CHEN XG (2011) Biocompatibility and characteristics of chitosan/cellulose acetate microspheres for drug delivery. Front. Mater. Sci. 5 (4) 367-378. https://doi.org/10.1007/s11706-011-0146-0 